\title{
Antiangiogenic therapy in diabetic nephropathy: A double-edged sword (Review)
}

\author{
QIAN-RU TAO ${ }^{1}$, YING-MING CHU ${ }^{2}$, LAN WEI $^{3}$, CHAO TU $^{3}$ and YUAN-YUAN HAN ${ }^{4}$ \\ ${ }^{1}$ Department of Nephrology, The Third Affiliated Hospital of Soochow University, Changzhou, Jiangsu 213000; \\ ${ }^{2}$ Department of Integrated Traditional Chinese Medicine, Peking University First Hospital, Beijing 100034; \\ ${ }^{3}$ Department of Internal Medicine, The Third Affiliated Hospital of Soochow University, Changzhou, \\ Jiangsu 213000; ${ }^{4}$ Institute of Medical Biology, Chinese Academy of Medical Sciences \\ \& Peking Union Medical College, Kunming, Yunnan 650118, P.R. China
}

Received August 20, 2020; Accepted January 21, 2021

DOI: $10.3892 / \mathrm{mmr} .2021 .11899$

\begin{abstract}
Diabetes and the associated complications are becoming a serious global threat and an increasing burden to human health and the healthcare systems. Diabetic nephropathy (DN) is the primary cause of end-stage kidney disease. Abnormal angiogenesis is well established to be implicated in the morphology and pathophysiology of DN. Factors that promote or inhibit angiogenesis serve an important role in DN. In the present review, the current issues associated with the vascular disease in DN are highlighted, and the challenges in the development of treatments are discussed.
\end{abstract}

Correspondence to: Dr Chao Tu, Department of Internal Medicine, The Third Affiliated Hospital of Soochow University, 185 Juqian Road, Changzhou, Jiangsu 213000, P.R. China

E-mail: tcmedical21@126.com

Dr Yuan-Yuan Han, Institute of Medical Biology, Chinese Academy of Medical Sciences \& Peking Union Medical College, 935 Jiaoling Road, Kunming, Yunnan 650118, P.R. China

E-mail: hyy@imbcams.com.cn

Abbreviations: ACEI, renin angiotensin enzyme inhibitors; Angs, angiopoietins; bFGF, basic fibroblast growth factor; CKD, chronic kidney disease; DN, diabetic nephropathy; ESRD, end-stage renal disease; GFR, glomerular filtration rate; GBM, glomerular basement membrane; HIF-1, hypoxia inducible factor-1; IGF-1, insulin-like growth factor-1; KBP, kallikrein-binding protein; OIR, oxygen-induced retinopathy; PDGF, platelet-derived growth factor; RAAS, renin-angiotensin-aldosterone system; RSV, resveratrol; PAR2, protease-activated receptor 2; sFLT-1, soluble FMS-like tyrosine kinase-1; TSP-1, thrombospondin-1; VASH1, vasohibin-1; VEGF, vascular endothelial growth factor

Key words: DN, ESRD, abnormal angiogenesis, promote angiogenesis, inhibits angiogenesis, antiangiogenic therapy

\section{Contents}

1. Introduction

2. Abnormal angiogenesis in $\mathrm{DN}$

3. Clinical and anti-angiogenic treatment

4. Other diabetic microvascular complications and treatments

\section{Introduction}

Diabetic nephropathy (DN) is clinically defined as microalbuminuria with or without other microvascular lesions or angiopathies, followed by a gradual increase in the extent of proteinuria and a decrease in the glomerular filtration rate, in a patient with long-term diabetes (1). DN is the primary cause of chronic kidney disease (CKD) that results in progressive renal hypofunction, with $\sim 50 \%$ of patients progressing to end-stage renal disease (ESRD) in the USA $(2,3)$. Studies on DN indicate that $20-30 \%$ patients with type I and II diabetes will progress to CKD and may eventually progress to $\operatorname{ESRD}(4,5)$.

The structural damage to the glomerular filtration barrier, as well as proteinuria are the primary features of DN, in addition to ultra-structural alterations, glomerular basement membrane thickening, mesangial matrix expansion, nodular glomerulosclerosis, arteriolar hyalinosis, podocyte foot process fusion and detachment (6). The occurrence of these injuries is due to the imbalance between the destructive factors (such as advanced glycation end products, free radicals, immune agents, andpro-inflammatory and pro-fibrotic molecules) and protective factors (such as anti-inflammatory agents, anti-ROS molecules and anti-fibrotic molecules) in the kidney (7-11).

Although glomerular mesangial cells and podocytes are considered to be the primary mediators of DN, the microvascular system damage caused by diabetes also serves a key role in the pathogenesis. Similar to diabetic retinopathy, biopsy in patients with type 1 diabetes showed increased glomerular capillary density and an increased number of glomerular efferent arterioles caused by glomerular neovascularization $(12,13)$. In addition, the glomerular expression of vascular growth factors, including angiogenin and vascular endothelial growth factor (VEGF) increases $(12,14,15)$, which 
may cause DN by promoting vascular leakage and decreasing transendothelial electrical resistance $(14,16)$.

At present, the treatment of DN is primarily aimed at controlling blood glucose levels and lowering blood pressure using specific types of blood pressure drugs that block the renin-angiotensin-aldosterone system (RAAS). RAAS inhibitors have been shown to exhibit renal protection in patients with DN, but it is not always certain whether their efficacy is sufficient. Similarly, in large clinical trials, strict blood glucose control has led to inconsistent benefits for patients with kidney disease. Therefore, once obvious DN occurs, in addition to the use of RAAS inhibitors to control blood pressure and blood glucose, specific therapies for the underlying mechanisms are also required to prevent DN developing into ESRD.

In several animal experiments, angiogenesis has been shown to be a potential target for the early treatment of DN. VEGF is the primary mediator of abnormal diabetic glomerular angiogenesis. Although the beneficial effects of anti-VEGF antibodies have been confirmed in diabetic animal experiments, recent basic and clinical evidence has suggested that blocking VEGF signaling can lead to proteinuria and renal thrombotic microangiopathy (17), indicating the importance of the normal levels of VEGF in the kidney. Therefore, anti-angiogenic treatment of DN should eliminate the excessive angiogenic response of the glomeruli without accelerating endothelial damage. Some endogenous anti-angiogenic factors, such as tumorstatin and endostatin, inhibit the excessive activation of endothelial cells, but do not specifically block the signal transduction of VEGF. In addition, the novel endothelial-derived anti-angiogenic factor vasohibin-1 (VASH1) improves stress tolerance and the survival of endothelial cells, and inhibits excessive angiogenesis. These anti-angiogenic factors have been shown to inhibit proteinuria and glomerular changes in diabetic mouse models (18). Therefore, anti-angiogenic treatments with promising drug candidates may improve the renal prognosis of patients with early DN.

In the present review, the formation and possible causes of abnormal angiogenesis in DN are summarized, and integrated related treatment options are discussed, with the aim of highlighting potential novel avenues for future research and clinical treatment.

\section{Abnormal angiogenesis in $\mathrm{DN}$}

Angiogenesis refers to the physiological and pathological process of neovascularization based on already present vessels. It is associated with embryogenesis, wound healing, tumor growth and metastasis, atherosclerosis and human inflammatory diseases (19). Abnormal angiogenesis is always associated with the morphology and pathophysiology of DN. Initially, it was reported that the formation of new blood vessels in the glomeruli of patients with type I and II diabetes represented abnormal angiogenesis $(12,20,21)$, and abnormal blood vessels were discovered in the glomerular tuft area, the glomerular vascular pole and Bowman's capsule $(21,22)$. A large number of proangiogenic and anti-angiogenic factors are involved in the regulation of angiogenesis, including VEGF, angiopoietins, fibroblast growth factors (FGFs), transforming growth factor-1 $\beta$ (TGF-1 $\beta$ ) and ephrin, amongst others.

\section{Proangiogenic factors}

VEGFs. As is presented in Table I, VEGF or VEGF-A is a critical inducer of angiogenesis, and its expression in the glomerulus is involved in the pathogenesis of DN. It has been suggested that the oxygen-regulated protein $150 \mathrm{kDa}$ (ORP150) may be involved in the development of proteinuria by regulating VEGF secretion in DN, as ORP150 expression is upregulated in patients with DN (23). Blockade of VEGF signaling with the pan-VEGF receptor tyrosine kinase inhibitor, SU5416, ameliorated diabetic (type II) albuminuria in a mouse model (24). Administration of neutralizing anti-VEGF antibodies in type I and II diabetic animals decreased proteinuria and glomerular hypertrophy $(16,25,26)$. Treatment with resveratrol, a polyphenol with anti-angiogenic activity, decreased the increase in glomerular diameter, mesangium accumulation, glomerular basement membrane thickness and renal fibrosis in a DN rat model, by decreasing the expression of pro-angiogenic factors, such as VEGF (27). Chemerin is a fat cell factor that participates in regulating inflammation. A previous study reported that the expression of chemerin and VEGF was associated with inflammatory factors and renal function in a DN rat model (28). Intravitreal injections of VEGF inhibitors can lead to a chronic decline in renal function (29). Additionally, the activation of protease-activated receptor 2 (PAR2) can generally exacerbate diabetic kidney disease, but PAR2 can protect against VEGF inhibitor-induced kidney damage (30).

The VEGF-A gene produces five closely associated subtypes via alternative splicing, and the most abundantly expressed species is $V E G F-A_{165}$, which encodes a glycoprotein with $20 \%$ homology to the $\mathrm{A}$ and $\mathrm{B}$ chains of platelet-derived growth factor (PDGF) (31). Renal VEGF-A gene expression is increased at the early stages and remains high at the later stages of diabetes in rats (32). There have been controversial results regarding the expression of $V E G F-A$ in glomeruli of DN. Immunohistochemical analysis of renal biopsy showed that VEGF-A expression in the glomeruli was increased in the early stages of DN (33). However, the expression of $V E G F-A$ mRNA in the glomeruli of patients with DN was decreased by oligonucleotide microarray analysis (34). The increase of VEGF-A expression in the serum of patients with type II diabetes is associated with blood glucose control, high levels of the sensitive C-reactive protein and proteinuria, suggesting that $V E G F-A$ is a biomarker of diabetic inflammation and nephropathy (35). Serum $V E G F-A$ levels are significantly correlated with hypoxia inducible factor-1 (HIF-1) and insulin-like growth factor-1 (IGF-1), which is hypothesized to be associated with the pathogenesis of DN (36). Podocyte specific VEGF-A heterozygous deficient mice showed proteinuria and glomerular endothelial damage similar to preeclampsia, whereas podocyte-specific $V E G F-A_{165}$ overexpressing mice showed significant striking collapsing glomerulopathy (37). VEGF-A decreases the levels of inhibitory complement factor $\mathrm{H}$ in the kidney, and this known genetic alteration is a feature of hereditary thrombotic microangiopathy, suggesting that $V E G F-A$ is involved in the local regulation of the complement system (38). Under the control of $\alpha-1$ antitrypsin promoter, transgenic rabbits expressing $V E G F-A_{165}$ in the kidney and liver also showed progressive proteinuria and renal dysfunction, early glomerular capillary hyperplasia and podocyte hypertrophy, late glomerular sclerosis and glomerular villus collapse (39). 
Eremina et al (40) found that when the VEGF-A gene was conditionally deleted from the podocytes of adult mice, an increase in proteinuria, thrombus and capillary ring occlusion in capillaries and endothelial cell swelling were observed, which is similar to renal thrombotic microangiopathy (40). On the other hand, overexpression of $V E G F-A$ in podocytes of adult transgenic mice leads to proteinuria, glomerular enlargement, glomerular basement membrane thickening, mesangial expansion and podocyte disappearance (41). In addition, overexpression of mutant $V E G F-A$, which selectively stimulates VEGFR-2, leads to mesangial matrix expansion and endothelial cell proliferation (42). In a case-controlled study, it was shown that serum VEGF-A was more preferable than that in plasma as a marker reflecting diabetic control in patients with type II diabetes, since a large portion of VEGF-A is derived from platelets (35). Kidney injury was partially prevented using DIAVIT, a natural Vaccinium myrtillus (blueberry) and Hippophae Rhamnoides (sea buckthorn) extract, due to the alteration of VEGF-A splicing in type II DN, particularly with delphinidin (43).

VEGF is a heparin-binding growth factor specific for vascular endothelial cells to promote angiogenesis in vivo (44). VEGF-A increases vascular permeability and monocyte chemotaxis $(45,46)$. VEGF-A binds to tyrosine kinase receptor VEGFR-1 (Flt-1) and VEGFR-2 (KDR/Flk-1), activating them (47). The angiogenic signal primarily comes from VEGF-A binding to VEGFR-2, whereas VEGFR-1 can be used as a negative regulator of VEGF-A, at least under certain conditions, such as embryogenesis (1). In addition, the activation of VEGFR-2 inhibits the apoptosis of endothelial cells via a PI3K Akt pathway (48). The synergistic effect of hyperglycemia and increased VEGF-A levels in diabetic glomerulopathy can be explained by the unique hypothesis of 'VEGF-endothelial nitric oxide (NO) uncoupling' (49,50).

VEGF-B is expressed predominantly in renal medullary tubular cells, but not in glomeruli, and its receptor, VEGFR-1, is expressed in endothelial cells (51). Inhibition of VEGF-B can prevent the histological changes and renal dysfunction in diabetic mice, and particularly blocks the lipotoxicity of podocytes and improves insulin resistance (52).

Angiopoietins (Angs). Angs are a family of vascular growth factors that regulate vascular remodeling, maturation and stability. The Angs family includes Ang1, Ang2 and Ang4 (human homologous gene of mouse Ang3), and they interact with tyrosine kinase receptors (Tie1 and Tie2). Ang-Tie signaling is involved in different processes of vascular development and remodeling in different diseases. Angiotensin converting enzyme (ACE) also regulates vascular reactivity by regulating the production of nitric oxide (NO) $(53,54)$.

In streptozotocin (STZ)-induced type 1 diabetic mice, the alteration of the milieu of vascular growth factors include a decrease in Ang1 levels, increase in VEGF-A levels, decrease in soluble VEGFR1 expression, and increase in phosphorylation of VEGFR2 (55). This alteration is accompanied by significant proteinuria, renal hypertrophy, hyperfiltration, ultrastructural changes of glomeruli and abnormal angiogenesis (55). Podocyte-specific inducible repletion of Ang1 can decrease proteinuria by $70 \%$ and prevent the proliferation of glomerular endothelial cells induced by diabetes (55). Ang2 levels are increased significantly in STZ-injected rat models and in diabetic patients (56).

Cartilage oligomeric matrix protein (COMP)-Ang1, a synthetic soluble, stable, and potent Ang1 variant, can phosphorylate the Tie 2 receptor and Akt, and promote angiogenesis in vitro and in vivo (57). Lee et al (58) found that delivery of COMP-Ang1 in a type 2 diabetes model decreased mesangial dilation, basement membrane thickening and proteinuria, and significantly improved hyperglycemia (58). Ang1 redelivery increased ser1177 phosphorylation of endothelium nitric oxide synthase to maintain NO levels, and thus, the integrity of capillaries and endothelial cells $(59,60)$. The overexpression of podocyte-specific Ang1 contributes to the stability of capillaries, in parallel to the decreased proliferation of glomerular endothelial cells in DN $(55,61)$.

FGFs. It was suggested that FGF-1 has beneficial anti-inflammatory and renal protective activity in vivo. Recombinant FGF1 significantly inhibited renal inflammation, glomerular and tubular injury, and renal insufficiency in type I and II diabetic mice (62). FGF1 can correct the hyperglycemia in type II, but not in type I diabetic mice $(62,63)$.

The administration of FGF21 can prevent renal lipid accumulation, oxidative stress, inflammation and fibrosis in mice after treatment with excessive fatty acids or STZ (64). The circular RNA, CIRC_0080425, significantly increased the expression of FGF11, through competitive binding with miR-24-3p, indirectly promoting DN (65). FGF21 negatively regulates the EMT process mediated by TGF- $\beta$-MDM $2 / \mathrm{Smad} 2 / 3$ signaling by activating Akt/MDM2/p53 signaling pathway, so as to prevent renal fibrosis in DN (66). Conversely, in DN, serum FGF21 levels are associated with the severity of proteinuria and the rapid loss of glomerular filtration rate, which may be a biomarker of poor prognosis (67). Serum FGF21 levels are closely associated with the occurrence of nephropathy in type II diabetic patients, and is an independent predictor of functional renal loss (68). FGF21 is expressed in glomerular mesangial cells and in renal tubular epithelial cells of diabetic mice (69), and blocking the expression of FGF21 can aggravate fibrogenesis in mesangial cells induced by high glucose (70).

Diabetes-associated factors may affect plasma FGF23 levels, which are associated with the progression of CKD (71). High FGF23 levels seem to contribute to increased cardiovascular and mortality risks in type II diabetes patients, and this risk is significantly increased in DN (72).

Therefore, FGF/FGFR signaling in DN is more likely to induce fibrosis. Their role in angiogenesis is not direct, but instead mediated via regulation of members of the RTK family, such as Eph receptors and PDGFRs (73).

$T G F-1 \beta$. In animal experiments, TGF-1 neutralizing antibodies and TGF-1 signal transduction inhibitor can effectively alleviate DN renal fibrosis (74). However, a clinical study of TGF-1 neutralizing antibodies failed to prove a sufficient effect on renal function in DN (74).

\section{Angiogenesis inhibitors}

Cell secretory proteins. (i) Pigment epithelium-derived factor $(P E D F)$. PEDF was first purified from the human retinal pigment epithelial cells (75) and was further identified as a 
member of the serine protease inhibitor (Serpin) family (76). Dawson et al (77) found that PEDF inhibited the proliferation of endothelial cells in a dose-dependent manner. Therefore, $\mathrm{PEDF}$ is regarded as the most potent endogenous angiogenesis inhibitor. Comparing the content of PEDF in the aqueous humor of patients with proliferative diabetic retinopathy (PDR) and non-PDRshowed that the levels of PEDF in the former significantlydecreased, which suggested that PEDF was the primary inhibitor of abnormal angiogenesis in human ocular tissues (78). Overexpression of PEDF in transgenic mice can effectively inhibit retinal neovascularization (79). PEDF expression is decreased in DN $(80,81)$, and administration of recombinant PEDF protein successfully inhibits retinal neovascularization in a rat model of diabetes (82). The potential mechanism of PEDF may be associated with blocking of the Wnt signaling pathway (83), as inhibition of the Wnt/ $\beta$-catenin signaling pathway can alleviate retinal vascular leakage and inhibit angiogenesis in diabetic rats (84). PEDF may also block p38 MAPK-GSK3- $\beta$-catenin signaling $(85,86)$ and significantly decreased ATP production in agreement with direct binding to cell-surface ATP synthase to exert the antiangiogenic activity (87). PEDF is able to block VEGF-induced angiogenesis via a $\gamma$-secretase-dependent pathway and by preventing dissociation of endothelial tight junction and adherens junction (88).

(ii) Kallikrein-binding protein (KBP/kallistatin). Kallikrein-binding protein (KBP), also termed SERPINA3K, was identified in human plasma as a Serpin (89). KBP is primarily synthesized and secreted by the liver, and it can bind to kallikrein in human tissues, inhibiting its function (90). KBP exerts pleiotropic effects on relaxation of blood vessels, and inhibits angiogenesis and antioxidative stress $(90,91)$. Increased levels of circulating KBP are found in diabetic patients with microvascular complications (91), which is likely due to KBP binding with LRP6, thus inhibiting the proliferation of endothelial cells by antagonizing the classical Wnt signaling pathway (92). In an oxygen-induced retinopathy (OIR) model, KBP overexpression attenuated hypoxia-induced retinal angiogenesis and vascular permeability (93).

(iii) Thrombospondin (TSP)-1. The TSPs are a family of calcium-binding glycoproteins that are secreted by the majority of cell types and participate in transient or longer-term interactions with other extracellular matrix components, termed matricellular proteins. TSP-1 is primarily secreted by platelets, endothelial cells and tumor cells, and is present in the plasma and extracellular matrix. TSP-1 is regarded as a regulator of angiogenesis via interactions with $\alpha \mathrm{v} \beta 3$ integrin, MMP9, VEGF, FGF-2, MMP-2 and TIMP-2 (94). At the retinal level, TSP-1 supports retinal pigment epithelium cell structure and inhibits vascular endothelial cell adhesion (95). An in vivo study performed on Akita/+ male mice deficient in TSP-1 aggravated the pathological angiogenesis of diabetic retinopathy (96).

TSP-1 has specific cell surface receptors, including CD36 and CD47 (97). TSP-1/CD36 binding was shown to activate apoptosis by inducing p38 and Jun N-terminal kinase, and subsequently the cell-surface expression of Fas-L. Ligation of Fas by Fas-L stimulated a caspase cascade and ultimately apoptotic cell death (98). TSP-1/CD47 is an important factor mediating MWCNT-induced microvascular dysfunction, which disrupts $\bullet$ NO signaling and enhances leukocyte-endothelial interactions (99).

(iv) Soluble FMS-like tyrosine kinase-1 (sFLT-1). SFLT-1 is a soluble form of VEGFR-1, which can bind with VEGF-A, VEGF-B and is a powerful VEGF antagonist (100). Overexpression of sFLT-1 in podocytes of mice improves diabetic glomerulopathy and proteinuria (100). Overexpression of adeno-associated virus transduced sFlt-1 in $\mathrm{db} / \mathrm{db}$ mice can decreasealbuminuria and improve podocyte injury (101). Adenovirus-mediated sFlt-1-induced proteinuria and glomerular endothelial proliferation similar to VEGF-A deficiency in mice (102).

(v) VASH-1. Vasohibin is an endothelium-derived negative feedback regulator of angiogenesis, which can be induced by VEGF in endothelial cells (103). Certain basic amino acid residues in the C-terminus of VASH-1 are important for heparin binding and its anti-angiogenic activities (104). The secretion and anti-angiogenic activity of VASH-1 requires the co-expression of small vasohibin-binding protein (105). The mechanism may be associated with the degradation of HIF-1 $\alpha$, which is mediated by prolyl hydroxylase (106). VASH-1 increases the stress tolerance of endothelial cells and promotes their survival (107). VASH-1 gene knockout can induce senescence of endothelial cells, which are prone to death due to cell stress (108), whereas overexpression of VASH-1 made endothelial cells resistant to premature aging and stress-induced cell death, and increased the expression of superoxide dismutase 2 and sirtuin 1 (108). The number of VASH-1-positive cells was positively associated with VEGFR-2 positive area and crescent formation (109). VASH-1 overexpression can significantly improve glomerular hypertrophy, glomerular filtration, proteinuria and glomerular endothelial area expansion in diabetic mice (18). Recombinant human VASH-1 also blocked high glucose-induced VEGFR-2 phosphorylation in a dose-dependent manner (18). Type I diabetes induced by STZ, increased proteinuria, glomerular hypertrophy, mesangial matrix accumulation and decreased diaphragmatic density in VASH-1 heterozygous mice (110). The positive area of glomerular CD31 and the expression of VEGF-A in kidney of VASH-1 heterozygous deficient mice was higher compared with diabetic wild-type mice (110). Endogenous VASH-1 may prevent angiogenesis of diabetic glomeruli and inflammation, as the anti-inflammatory effect of endogenous VASH-1 has also been confirmed in a unilateral ureteral obstruction model (111).

(vi) Matrix metalloproteinases (MMPs). MMP-7 expression is increased in the renal biopsy tissues of patients with diabetic nephropathy, and its levels are closely associated with the abundance of $\beta$-Catenin (112).

\section{Hydrolytic fragments of precursor proteins}

(i) Endostatin. Endostatin, a putative anti-angiogenic factor, is a 20-kDa proteolytic fragment of collagen XVIII (113). In vitro, it can inhibit the proliferation, migration and catheter formation of endothelial cells induced by VEGF (114). The interaction between endostatin and $\alpha 5 \beta 1$ integrin resulted in the inhibition 
of FAK and the subsequent inhibition of MAPK (115). Endostatin inhibits glomerular VEGF-A primarily produced by podocytes in diabetic mice (116). In type I diabetic mice, endostatin significantly inhibited proteinuria and histological changes (116). The levels of circulating endostatin in patients with type II diabetic nephropathy is high, which suggests that endostatin may possess clinical value as a risk marker of diabetic nephropathy (117). Additionally, endostatin can decrease glomerular hypertrophy, hyperfiltration and proteinuria in STZ induced diabetic mice (116). Endostatin also significantly inhibits mesangial matrix expansion, extracellular matrix accumulation, endothelial cell proliferation and monocyte/macrophage infiltration (116). Anti-angiogenic endostatin polypeptide improves early renal lesions in a model of type I diabetic nephropathy (116). Circulating endostatin levels can predict progression and mortality of kidney disease, independently of established renal disease markers in type II diabetic patients (117).

(ii) Tumstatin. Tumstatin is derived from the type IV collagen $\alpha 3$ chain, which can inhibit pathological angiogenesis by inhibiting endothelial cell proliferation (118), by binding to the $\alpha \mathrm{V} \beta 3$ integrin of endothelial cells (119). Tumstatin acts as a specific inhibitor of endothelial cell protein synthesis through inhibition of the activation of FAK, protein kinase B (PKB/Akt), PI3-kinase and mammalian target of rapamycin (120). Tumor suppressor peptides significantly inhibited proteinuria and glomerular histological changes in diabetic mice, and increased the number of glomerular capillaries (121). Injection of tumstatin decreased glomerular hypertrophy, hyperfiltration and proteinuria in STZ-induced diabetic mice (121). It also inhibited the increase in the levels of VEGF-A and VEGFR-2 in kidneys induced by diabetes (121). Due to the high expression of $\alpha \mathrm{V} \beta 3$ integrin in podocytes (122), the primary target of tumstatin may not be endothelial cells, but instead podocytes.

(iii) Angiostatin/Kringle1-4. Angiostatin is a protective fragment of plasminogen, which can inhibit tumor angiogenesis (123). Adenovirus mediated angiostatin can significantly improve proteinuria and glomerular hypertrophy in type I diabetic rats (124). In a model of CKD induced by a subtotal nephrectomy, angiostatin treatment decreased the number of peritubular capillaries and urinary nitric oxide levels (125). In vitro, angiostatin decreased the upregulated expression of VEGF and TGF- $\beta$ in human mesangial cells induced by high glucose, and increased the levels of pigment epithelium-derived factor, an endogenous DN inhibitor (124).

(iv) Kringle5 (K5). K5 is the fifth domain of human plasminogen associated with angiostatin (K1-4). Its molecular weight is only $16 \mathrm{kDa}$ and it is the most active anti-angiogenic fragment in human plasminogen (126). In an OIR and STZ-induced rat model, K5 inhibited retinal neovascularization (127). Additionally, K5-induced endothelial cell apoptosis was shown to be mediated by a positive feedback loop involving VDAC1-AKT-GSK3 $\beta$-VDAC1 (128), which resulted in inhibition of angiogenesis.

Others. Netrin-1 and UNC5B were shown to be upregulated in STZ-induced rats, and UNC5B upregulation contributed partly to enhancing angiogenesis in DN (129). PDE5 inhibitors exert protective effects by improving perivascular inflammation through modulating miR-22 and BMP7 in a DN mouse model (130). The Slit2/Robol signaling pathway is involved in angiogenesis of glomerular endothelial cells in a diabetic-like environment (131). Neurite outgrowth inhibitor-B serves an important role in vascular remodeling, which protects the vasculature system in a model of DN (132).

Angiogenesis vs. vasculogenesis. Angiogenesis is the process by which fewer blood vessels branch and bud to form off shoot vessels. Vasculogenesis is the process in which endothelial cells differentiate from endothelial progenitor cells to connect and form a tube, ultimately resulting in the formation of new blood vessels.

\section{Clinical and anti-angiogenic treatment}

The early diagnosis of DN (stage I DN) includes thickening of the glomerular basement membrane and renal tubular basement membrane, whereas after glomerular thickening, the mesangial cell dilation is considered stage II DN (133). The expansion of the mesangium further leads to glomerular leakage combined with the accumulation of fibronectin and type IV collagen, which also leads to nodular sclerosis (stage III DN) (133). Increased potassium secretion and angiogenesis signals are early renal responses in human DN (134).

Renin angiotensin enzyme inhibitors (such as ACEI or ARB) should be administered as soon as possible, as both of these can decrease systemic and intraglomerular blood pressure by inhibiting the action of ACEII on angiotensin II type 1 receptor (AT1) receptor (1). ACEI lowers the production of angiotensin II (135), whereas the AT1 antagonists block the AT1 receptor (136). It has been reported that proteinuria and hypertension are common complications (137). In nodular diabetic glomerulopathy, there are vascular mesangial channels, which serve as indicators of the changes in neovascularization and blood flow in these glomeruli (138). Nilotinib hydrochloride is a highly potent tyrosine kinase inhibitor that can inhibit the progress of DN via the regulation of a variety of mechanisms (139).

It has been shown that promoting anti-angiogenesis (particularly via anti-VEGF mechanisms) may be a promising strategy for management of the early stages of DN, based on several animal experiments (1). However, there are currently no anti-VEGF-A based treatments for patients with DN. In some studies, patients with DN who received intravitreal injection of VEGF-A inhibitors have shown contrasting results; that is renal damage associated with glomerular microangiopathy, including thickening of the capillary wall and glomerular basement membrane (140), or rapidly worsening proteinuria and decreased kidney function (141). Therefore, therapies involving anti-VEGF-A in DN should first aim to maintain physiological levels of VEGF-A. Otherwise, excessive inhibition of VEGF-A may cause harmful side effects. Recently, a study on patients with early DN showed that intravitreal injection of bevacizumab resulted in worsening proteinuria and renal function, and this was improved using ranibizumab, which had a lower potency (13).

The vasohibin family may participate in mesangial expansion by mediating VEGFR2 signaling. Current studies indicate 


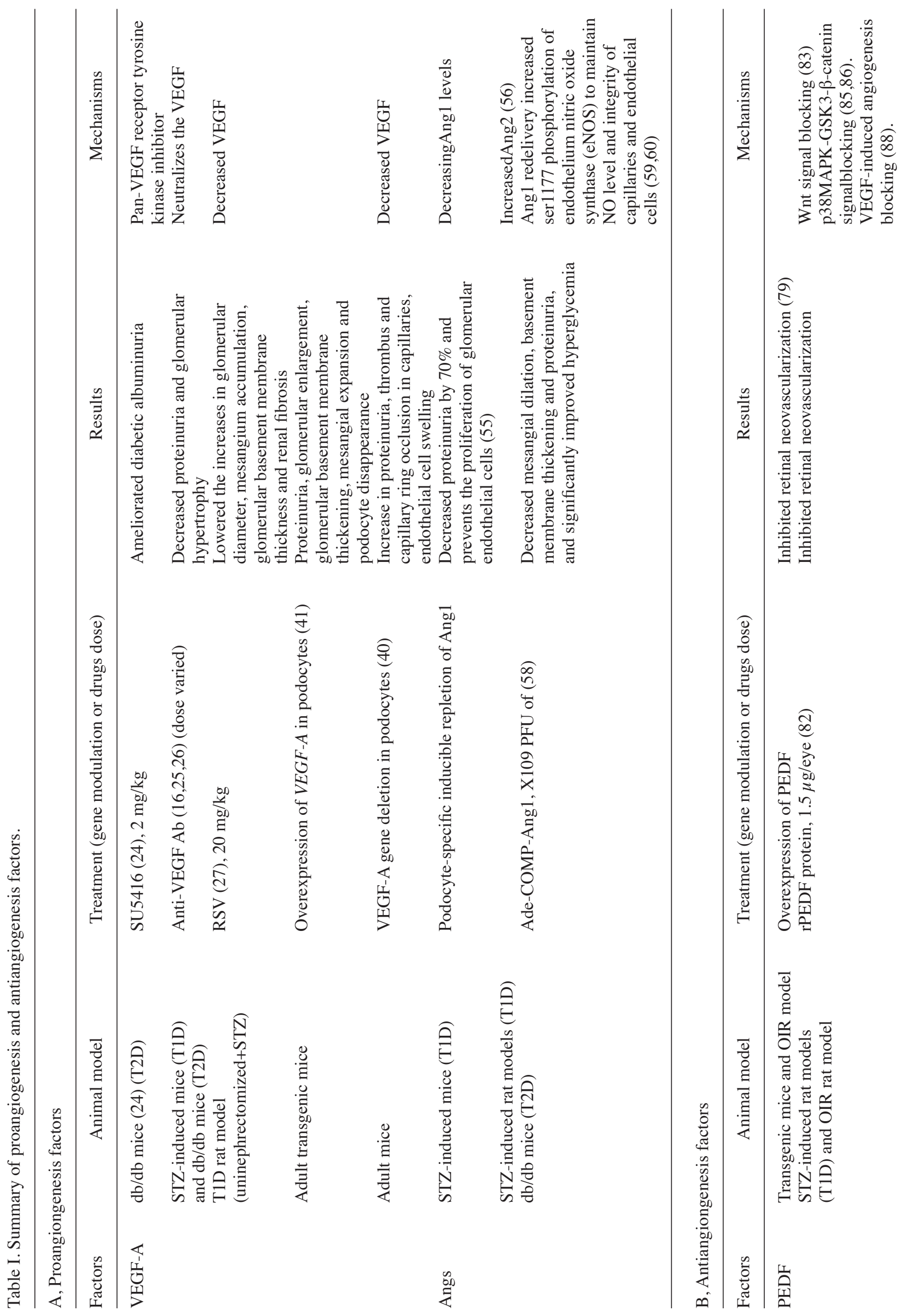




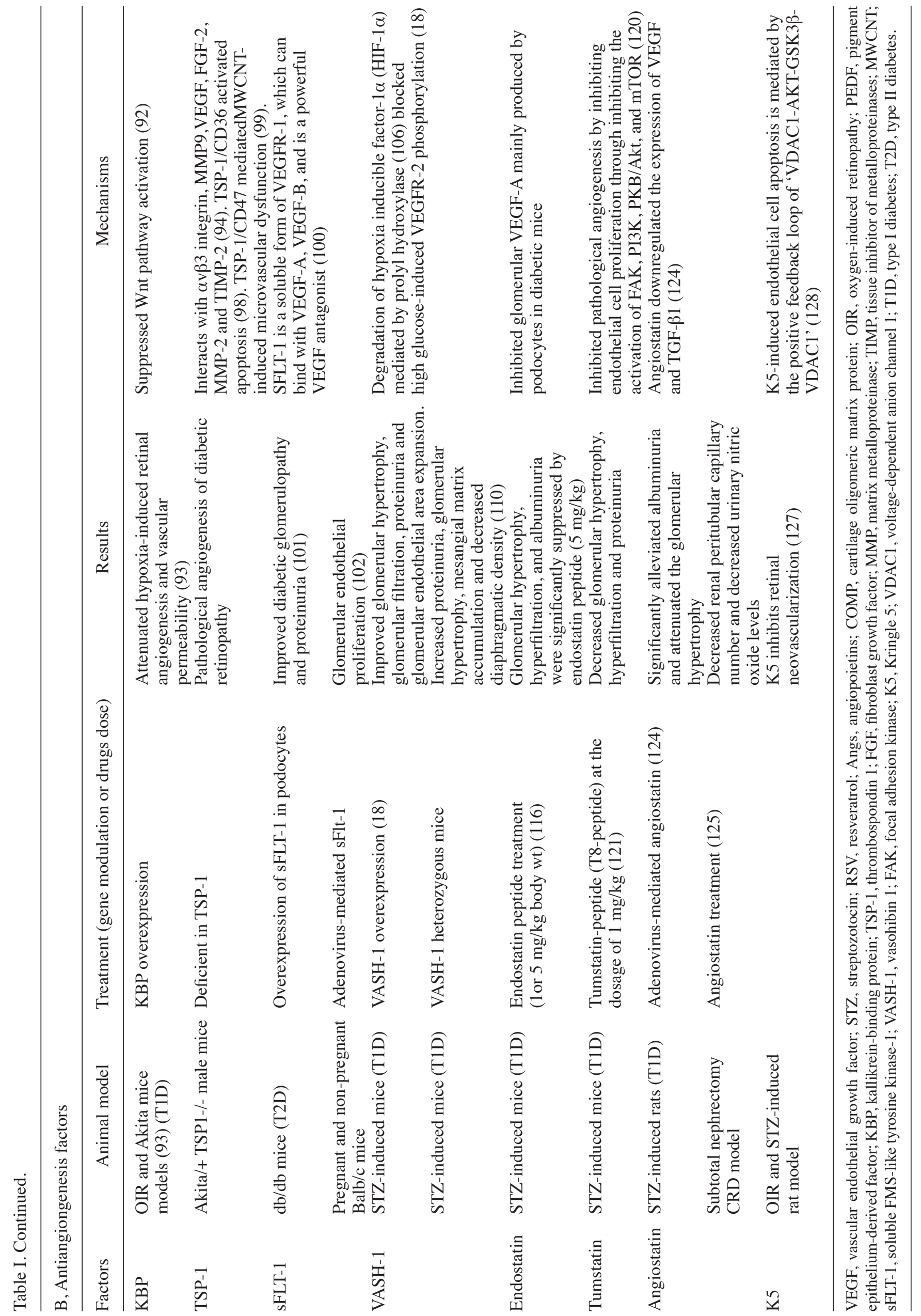


that the vasohibin family may be a promising therapeutic target to reduce excessive angiogenesis and renal fibrosis in $\mathrm{DN}$, however, further research is required to understand their relevance and clinical significance.

\section{Other diabetic microvascular complications and treatments}

Other diabetic microvascular complications include diabetic retinopathy, erectile dysfunction, macular oedema (DMO) and diabetic foot. Diabetic patients with retinal microvascular lesions, pericytes necrosis, endothelial barrier function damage and blood components from the blood vessels in the tissue, result in retinal lesions and dysfunction. This may be due to the fact that high glucose can induce the apoptosis of pericytes in diabetic retina, damaging the blood retinal barrier and activating vascular endothelial cells, thus promoting vascular budding and angiogenesis. Almost all cells in the retina can secrete VEGF under the stimulation of ischemia and hypoxia. A large amount of clinical data has shown that VEGF levels in the vitreous cavity of patients with PDR is significantly increased (142). Treatments include panretinal photocoagulation, intravitreal injection of bevacizumab, aflibercept or ranibizumab, and surgery. Resveratrol may improve diabetic retinopathy by regulating the expression of PEDF and TSP-1 (143). PDE5 inhibitors (such as sildenafil and tadalafil) are currently used in the treatment of diabetic erectile dysfunction. PDGF can promote cell migration and smooth muscle proliferation and accelerate wound healing (144). In addition, recombinant VEGF (145), EGF (146), FGF (147), TGF- $\beta$ (148) and IGF-1 (149) can be used treatment of diabetic foot. DMO is a common complication of diabetic retinopathy, and antiangiogenic therapy with anti-VEGF can decreaseoedema, improve vision and prevent further visual loss (150).

\section{Acknowledgements}

Not applicable.

\section{Funding}

This work is supported by Yunnan Fundamental Research Projects (grant no. 202001AT070145).

\section{Availability of data and materials}

Not applicable.

\section{Authors' contributions}

QRT drafted the majority of the review. YMC contributed to drafting the review. LW revised the review. CT conceptualized the review. YYH participated conceptualizing and designing the review, and participated in drafting and reviewing the review. All authors read and approved the final manuscript.

\section{Ethics approval and consent to participate}

Not applicable.

\section{Patient consent for publication}

Not applicable.

\section{Competing interests}

The authors declare that they have no competing interests.

\section{References}

1. Tanabe K, Maeshima Y, Sato Y and Wada J: Antiangiogenic therapy for diabetic nephropathy. Biomed Res Int 2017: 5724069, 2017.

2. Collins AJ, Foley RN, Herzog C, Chavers B, Gilbertson D, Ishani A, Kasiske B, Liu J, Mau LW, McBean M, et al: US renal data system 2010 annual data report. Am J Kidney Dis 57 (Suppl 1): A8, e1-e526, 2011.

3. Thomas MC, Cooper ME and Zimmet P: Changing epidemiology of type 2 diabetes mellitus and associated chronic kidney disease. Nat Rev Nephrol 12: 73-81, 2016.

4. Adler AI, Stevens RJ, Manley SE, Bilous RW, Cull CA and Holman RR; UKPDS Group: Development and progression of nephropathy in type 2 diabetes, the United Kingdom prospective diabetes study (UKPDS 64). Kidney Int 63: 225-232, 2003.

5. Retnakaran R, Cull CA, Thorne KI, Adler AI and Holman RR; UKPDS Study Group: Risk factors for renal dysfunction in type 2 diabetes, U.K. prospective diabetes study 74. Diabetes 55: 1832-1839, 2006.

6. Bayliss G, Weinrauch LA and D'Elia JA: Pathophysiology of obesity-related renal dysfunction contributes to diabetic nephropathy. Curr Diab Rep 12: 440-446, 2012.

7. Collins AJ, Foley RN, Chavers B, Gilbertson D, Herzog C, Ishani A, Johansen K, Kasiske BL, Kutner N, Liu J, et al: US renal data system 2013 annual data report. Am J Kidney Dis 63 (Suppl 1): A7, 2014.

8. Fernandez-Fernandez B, Ortiz A, Gomez-Guerrero C and Egido J: Therapeutic approaches to diabetic nephropathy-beyond the RAS. Nat Rev Nephrol 10: 325-346, 2014.

9. Navarro-Gonzalez JF, Mora-Fernandez C, Muros de Fuentes M and Garcia-Perez J: Inflammatory molecules and pathways in the pathogenesis of diabetic nephropathy. Nat Rev Nephrol 7: 327-340, 2011.

10. Tuttle KR: Linking metabolism and immunology: Diabetic nephropathy is an inflammatory disease. J Am Soc Nephrol 16: $1537-1538,2005$.

11. Wada $\mathbf{J}$ and Makino $\mathrm{H}$ : Innate immunity in diabetes and diabetic nephropathy. Nat Rev Nephrol 12: 13-26, 2016.

12. Kanesaki Y, Suzuki D, Uehara G, Toyoda M, Katoh T, Sakai H and Watanabe T: Vascular endothelial growth factor gene expression is correlated with glomerular neovascularization in human diabetic nephropathy. Am J Kidney Dis 45: 288-294, 2005.

13. Hanna RM, Abdelnour L, Hasnain H, Selamet U and Kurtz I: Intravitreal bevacizumab-induced exacerbation of proteinuria in diabetic nephropathy, and amelioration by switching to ranibizumab. SAGE Open Med Case Rep 8: 2050313X20907033, 2020.

14. Satchell SC, Anderson KL and Mathieson PW: Angiopoietin 1 and vascular endothelial growth factor modulate human glomerular endothelial cell barrier properties. J Am Soc Nephrol 15: 566-574, 2004.

15. Tsilibary EC: Microvascular basement membranes in diabetes mellitus. J Pathol 200: 537-546, 2003.

16. de Vriese AS, Tilton RG, Elger M, Stephan CC, Kriz W and Lameire NH: Antibodies against vascular endothelial growth factor improve early renal dysfunction in experimental diabetes. J Am Soc Nephrol 12: 993-1000, 2001.

17. Filek R, Hooper P, Sheidow TG, Liu H, Chakrabarti S and Hutnik CM: Safety of anti-VEGF treatments in a diabetic rat model and retinal cell culture. Clin Ophthalmol 13: 1097-1114, 2019.

18. Nasu T, Maeshima Y, Kinomura M, Hirokoshi-Kawahara K, Tanabe K, Sugiyama H, Sonoda H, Sato Y and Makino H: Vasohibin-1, a negative feedback regulator of angiogenesis, ameliorates renal alterations in a mouse model of diabetic nephropathy. Diabetes 58: 2365-2375, 2009.

19. Folkman J: Angiogenesis in cancer, vascular, rheumatoid and other disease. Nat Med 1: 27-31, 1995. 
20. Hohenstein B, Hausknecht B, Boehmer K, Riess R, Brekken RA and Hugo CP: Local VEGF activity but not VEGF expression is tightly regulated during diabetic nephropathy in man. Kidney Int 69: 1654-1661, 2006.

21. Osterby R and Nyberg G: New vessel formation in the renal corpuscles in advanced diabetic glomerulopathy. J Diabet Complications 1: 122-127, 1987.

22. Osterby R, Bangstad HJ, Nyberg G and Rudberg S: On glomerular structural alterations in type-1 diabetes. Companions of early diabetic glomerulopathy. Virchows Arch 438: 129-135, 2001.

23. Wang DQ, Miao XJ, Gao J, Zhou YH, Ji FY and Cheng XB The $150-\mathrm{kDa}$ oxygen-regulated protein (ORP150) regulates proteinuria in diabetic nephropathy via mediating VEGF. Exp Mol Pathol 110: 104255, 2019.

24. Sung SH, Ziyadeh FN, Wang A, Pyagay PE, Kanwar YS and Chen S: Blockade of vascular endothelial growth factor signaling ameliorates diabetic albuminuria in mice. J Am Soc Nephrol 17: 3093-3104, 2006.

25. Flyvbjerg A, Dagnaes-Hansen F, De Vriese AS, Schrijvers BF, Tilton RG and Rasch R: Amelioration of long-term renal changes in obese type 2 diabetic mice by a neutralizing vascular endothelial growth factor antibody. Diabetes 51: 3090-3094, 2002.

26. Schrijvers BF, Flyvbjerg A, Tilton RG, Lameire NH and De Vriese AS: A neutralizing VEGF antibody prevents glomerular hypertrophy in a model of obese type 2 diabetes, the Zucker diabetic fatty rat. Nephrol Dial Transplant 21: 324-329, 2006.

27. Wen D, Huang X, Zhang M, Zhang L, Chen J, Gu Y and Hao CM: Resveratrol attenuates diabetic nephropathy via modulating angiogenesis. PLoS One 8: e82336, 2013.

28. Lin S, Teng J, Li J, Sun F, Yuan D and Chang J: Association of chemerin and vascular endothelial growth factor (VEGF) with diabetic nephropathy. Med Sci Monit 22: 3209-3214, 2016.

29. Hanna RM, Barsoum M, Arman F, Selamet U, Hasnain H and Kurtz I: Nephrotoxicity induced by intravitreal vascular endothelial growth factor inhibitors: Emerging evidence. Kidney Int 96: 572-580, 2019.

30. Oe Y, Fushima T, Sato E, Sekimoto A, Kisu K, Sato H, Sugawara J, Ito S and Takahashi N: Protease-activated receptor 2 protects against VEGF inhibitor-induced glomerular endothelial and podocyte injury. Sci Rep 9: 2986, 2019.

31. Ferrara N and Davis-Smyth T: The biology of vascular endothelial growth factor. Endocr Rev 18: 4-25, 1997.

32. Cooper ME, Vranes D, Youssef S, Stacker SA, Cox AJ, Rizkalla B, Casley DJ, Bach LA, Kelly DJ and Gilbert RE: Increased renal expression of vascular endothelial growth factor (VEGF) and its receptor VEGFR-2 in experimental diabetes. Diabetes 48 : 2229-2239, 1999

33. Cha DR, Kim NH, Yoon JW, Jo SK, Cho WY, Kim HK and Won NH: Role of vascular endothelial growth factor in diabetic nephropathy. Kidney Int Suppl 77: S104-S112, 2000.

34. Baelde HJ, Eikmans M, Doran PP, Lappin DW, de Heer E and Bruijn JA: Gene expression profiling in glomeruli from human kidneys with diabetic nephropathy. Am J Kidney Dis 43: 636-650, 2004

35. Hanefeld M, Appelt D, Engelmann K, Sandner D, Bornstein SR Ganz X, Henkel E, Haase R and Birkenfeld AL: Serum and plasma levels of vascular endothelial growth factors in relation to quality of glucose control, biomarkers of inflammation, and diabetic nephropathy. Horm Metab Res 48: 529-534, 2016.

36. Shao Y, Lv C, Yuan Q and Wang Q: Levels of Serum $25(\mathrm{OH})$ VD3, HIF-1 $\alpha$, VEGF, vWf, and IGF-1 and their correlation in type 2 diabetes patients with different urine albumin creatinine ratio. J Diabetes Res 2016: 1925424, 2016.

37. Eremina V, Sood M, Haigh J, Nagy A, Lajoie G, Ferrara N, Gerber HP, Kikkawa Y, Miner JH and Quaggin SE: Glomerularspecific alterations of VEGF-A expression lead to distinct congenital and acquired renal diseases. J Clin Invest 111: 707-716, 2003.

38. Keir LS, Firth R, Aponik L, Feitelberg D, Sakimoto S, Aguilar E, Welsh GI, Richards A, Usui Y, Satchell SC, et al: VEGF regulates local inhibitory complement proteins in the eye and kidney. J Clin Invest 127: 199-214, 2017.

39. Liu E, Morimoto M, Kitajima S, Koike T, Yu Y, Shiiki H, Nagata M, Watanabe $\mathrm{T}$ and Fan $\mathrm{J}$ : Increased expression of vascular endothelial growth factor in kidney leads to progressive impairment of glomerular functions. J Am Soc Nephrol 18 2094-2104, 2007.

40. Eremina V, Jefferson JA, Kowalewska J, Hochster H, Haas M, Weisstuch J, Richardson C, Kopp JB, Kabir MG, Backx PH, et al: VEGF inhibition and renal thrombotic microangiopathy. N Engl J Med 358: 1129-1136, 2008.
41. Veron D, Reidy KJ, Bertuccio C, Teichman J, Villegas G, Jimenez J, Shen W, Kopp JB, Thomas DB and Tufro A: Overexpression of VEGF-A in podocytes of adult mice causes glomerular disease. Kidney Int 77: 989-999, 2010.

42. Sato W, Tanabe K, Kosugi T, Hudkins K, Lanaspa MA, Zhang L, Campbell-Thompson M, Li Q, Long DA, Alpers CE and Nakagawa T: Selective stimulation of VEGFR2 accelerates progressive renal disease. Am J Pathol 179: 155-166, 2011.

43. Stevens M, Neal CR, Craciun EC, Dronca M, Harper SJ and Oltean S: The natural drug DIAVIT is protective in a type II mouse model of diabetic nephropathy. PLoS One 14: e0212910, 2019.

44. Leung DW, Cachianes G, Kuang WJ, Goeddel DV and Ferrara N: Vascular endothelial growth factor is a secreted angiogenic mitogen. Science 246: 1306-1309, 1989.

45. Bates DO and Curry FE: Vascular endothelial growth factor increases microvascular permeability via a $\mathrm{Ca}(2+)$-dependent pathway. Am J Physiol 273: H687-H694, 1997.

46. Barleon B, Sozzani S, Zhou D, Weich HA, Mantovani A and Marme D: Migration of human monocytes in response to vascular endothelial growth factor (VEGF) is mediated via the VEGF receptor flt-1. Blood 87: 3336-3343, 1996.

47. Guo D, Jia Q, Song HY, Warren RS and Donner DB: Vascular endothelial cell growth factor promotes tyrosine phosphorylation of mediators of signal transduction that contain SH2 domains. Association with endothelial cell proliferation. J Biol Chem 270: 6729-6733, 1995.

48. Gerber HP, McMurtrey A, Kowalski J, Yan M, Keyt BA, Dixit V and Ferrara N: Vascular endothelial growth factor regulates endothelial cell survival through the phosphatidylinositol 3'-kinase/Akt signal transduction pathway. Requirement for Flk-1/KDR activation. J Biol Chem 273: 30336-30343, 1998.

49. Nakagawa T, Sato W, Kosugi T and Johnson RJ: Uncoupling of VEGF with endothelial NO as a potential mechanism for abnormal angiogenesis in the diabetic nephropathy. J Diabetes Res 2013: 184539, 2013.

50. Nakagawa T: Uncoupling of the VEGF-endothelial nitric oxide axis in diabetic nephropathy: An explanation for the paradoxical effects of VEGF in renal disease. Am J Physiol Renal Physiol 292: F1665-F1672, 2007.

51. Muhl L, Moessinger C, Adzemovic MZ, Dijkstra MH, Nilsson I, Zeitelhofer M, Hagberg CE, Huusko J, Falkevall A, Ylä-Herttuala S and Eriksson U: Expression of vascular endothelial growth factor (VEGF)-B and its receptor (VEGFR1) in murine heart, lung and kidney. Cell Tissue Res 365: 51-63, 2016.

52. Falkevall A, Mehlem A, Palombo I, Heller Sahlgren B, Ebarasi L, He L, Ytterberg AJ, Olauson H, Axelsson J, Sundelin B, et al: Reducing VEGF-B signaling ameliorates renal lipotoxicity and protects against diabetic kidney disease. Cell Metab 25: 713-726, 2017.

53. Xu J, Lan D, Li T, Yang G and Liu L: Angiopoietins regulate vascular reactivity after haemorrhagic shock in rats through the Tie2-nitric oxide pathway. Cardiovasc Res 96: 308-319, 2012.

54. Kim KL, Shin IS, Kim JM, Choi JH, Byun J, Jeon ES, Suh W and Kim DK: Interaction between Tie receptors modulates angiogenic activity of angiopoietin 2 in endothelial progenitor cells. Cardiovasc Res 72: 394-402, 2006.

55. Dessapt-Baradez C, Woolf AS, White KE, Pan J, Huang JL, Hayward AA, Price KL, Kolatsi-Joannou M, Locatelli M, Diennet M, et al: Targeted glomerular angiopoietin-1 therapy for early diabetic kidney disease. J Am Soc Nephrol 25: 33-42, 2014.

56. Qiao L, Lu SL, Dong JY and Song F: Abnormal regulation of neo-vascularisation in deep partial thickness scalds in rats with diabetes mellitus. Burns 37: 1015-1022, 2011.

57. Cho CH, Kammerer RA, Lee HJ, Steinmetz MO, Ryu YS, Lee SH, Yasunaga K, Kim KT, Kim I, Choi HH, et al: COMP-Ang1, a designed angiopoietin-1 variant with nonleaky angiogenic activity. Proc Natl Acad Sci USA 101: 5547-5552, 2004.

58. Lee S, Kim W, Moon SO, Sung MJ, Kim DH, Kang KP, Jang KY, Lee SY, Park BH, Koh GY and Park SK: Renoprotective effect of COMP-angiopoietin-1 in $\mathrm{db} / \mathrm{db}$ mice with type 2 diabetes. Nephrol Dial Transplant 22: 396-408, 2007.

59. Predescu D, Predescu S, Shimizu J, Miyawaki-Shimizu K and Malik AB: Constitutive eNOS-derived nitric oxide is a determinant of endothelial junctional integrity. Am J Physiol Lung Cell Mol Physiol 289: L371-L381, 2005.

60. Babaei S, Teichert-Kuliszewska K, Zhang Q, Jones N, Dumont DJ and Stewart DJ: Angiogenic actions of angiopoietin-1 require endothelium-derived nitric oxide. Am J Pathol 162: 1927-1936, 2003. 
61. Nakagawa T, Kosugi T, Haneda M, Rivard CJ and Long DA Abnormal angiogenesis in diabetic nephropathy. Diabetes 58: 1471-1478, 2009.

62. Liang G, Song L, Chen Z, Qian Y, Xie J, Zhao L, Lin Q, Zhu G, Tan Y, Li X, et al: Fibroblast growth factor 1 ameliorates diabetic nephropathy by an anti-inflammatory mechanism. Kidney Int 93: 95-109, 2018.

63. Perry RJ, Lee S, Ma L, Zhang D, Schlessinger J and Shulman GI: FGF1 and FGF19 reverse diabetes by suppression of the hypothalamic-pituitary-adrenal axis. Nat Commun 6: 6980, 2015.

64.Zhang Y, Lei T, Huang JF, Wang SB, Zhou LL, Yang ZQ and Chen XD: The link between fibroblast growth factor 21 and sterol regulatory element binding protein 1c during lipogenesis in hepatocytes. Mol Cell Endocrinol 342: 41-47, 2011.

65. Liu H, Wang X, Wang ZY and Li L: Circ_0080425 inhibits cell proliferation and fibrosis in diabetic nephropathy via sponging miR-24-3p and targeting fibroblast growth factor 11. J Cell Physiol 235: 4520-4529, 2020.

66. Lin S, Yu L, Ni Y, He L, Weng X, Lu X and Zhang C: Fibroblast growth factor 21 attenuates diabetes-induced renal fibrosis by negatively regulating TGF- $\beta$-p53-Smad $2 / 3$-mediated epithelial-to-mesenchymal transition via activation of AKT. Diabetes Metab J 44: 158-172, 2020.

67. Suassuna PGA, de Paula RB, Sanders-Pinheiro H, Moe OW and $\mathrm{Hu}$ MC: Fibroblast growth factor 21 in chronic kidney disease. J Nephrol 32: 365-377, 2019.

68. Esteghamati A, Khandan A, Momeni A, Behdadnia A, Ghajar A Nikdad MS, Noshad S, Nakhjavani $M$ and Afarideh M: Circulating levels of fibroblast growth factor 21 in early-stage diabetic kidney disease. Ir J Med Sci 186: 785-794, 2017.

69. Kim HW, Lee JE, Cha JJ, Hyun YY, Kim JE, Lee MH, Song HK, Nam DH, Han JY, Han SY, et al: Fibroblast growth factor 21 improves insulin resistance and ameliorates renal injury in db/db mice. Endocrinology 154: 3366-3376, 2013.

70. Li S, Guo X, Zhang T, Wang N, Li J, Xu P, Zhang S, Ren G and Li D: Fibroblast growth factor 21 ameliorates high glucose-induced fibrogenesis in mesangial cells through inhibiting STAT5 signaling pathway. Biomed Pharmacother 93: 695-704, 2017.

71. Kuro-O M: Klotho in health and disease. Curr Opin Nephrol Hypertens 21: 362-368, 2012.

72. Yeung SMH, Bakker SJL, Laverman GD and De Borst MH: Fibroblast growth factor 23 and adverse clinical outcomes in type 2 diabetes: A bitter-sweet symphony. Curr Diab Rep 20: $50,2020$.

73. Xie Y, Su N, Yang J, Tan Q, Huang S, Jin M, Ni Z, Zhang B, Zhang D, Luo F, et al: FGF/FGFR signaling in health and disease. Signal Transduct Target Ther 5: 181, 2020.

74. Zhao L, Zou Y and Liu F: Transforming growth factor-betal in diabetic kidney disease. Front Cell Dev Biol 8: 187, 2020.

75. Steele FR, Chader GJ, Johnson LV and Tombran-Tink J: Pigment epithelium-derived factor, neurotrophic activity and identification as a member of the serine protease inhibitor gene family. Proc Natl Acad Sci USA 90: 1526-1530, 1993.

76. Becerra SP, Palmer I, Kumar A, Steele F, Shiloach J, Notario V and Chader GJ: Overexpression of fetal human pigment epithelium-derived factor in Escherichia coli. A functionally active neurotrophic factor. J Biol Chem 268: 23148-23156, 1993.

77. Dawson DW, Volpert OV, Gillis P, Crawford SE, Xu H, Benedict W and Bouck NP: Pigment epithelium-derived factor: A potent inhibitor of angiogenesis. Science 285: 245-248, 1999.

78. Ogata N, Matsuoka M, Matsuyama K, Shima C, Tajika A, Nishiyama T, Wada M, Jo N, Higuchi A, Minamino K, et al: Plasma concentration of pigment epithelium-derived factor in patients with diabetic retinopathy. J Clin Endocrinol Metab 92 1176-1179, 2007.

79. Park K, Jin J, Hu Y, Zhou K and Ma JX: Overexpression of pigment epithelium-derived factor inhibits retinal inflammation and neovascularization. Am J Pathol 178: 688-698, 2011.

80. Spranger J, Osterhoff M, Reimann M, Mohlig M, Ristow M, Francis MK, Cristofalo V, Hammes HP, Smith G, Boulton M and Pfeiffer AF: Loss of the antiangiogenic pigment epithelium-derived factor in patients with angiogenic eye disease Diabetes 50: 2641-2645, 2001

81. Gao G, Li Y, Zhang D, Gee S, Crosson C and Ma J: Unbalanced expression of VEGF and PEDF in ischemia-induced retinal neovascularization. FEBS Lett 489: 270-276, 2001.

82.Zhang SX, Wang JJ, Gao G, Shao C, Mott R and Ma JX: Pigment epithelium-derived factor (PEDF) is an endogenous antiinflammatory factor. FASEB J 20: 323-325, 2006.
83. Park K, Lee K, Zhang B, Zhou T, He X, Gao G, Murray AR and Ma JX: Identification of a novel inhibitor of the canonical Wnt pathway. Mol Cell Biol 31: 3038-3051, 2011.

84. Chen Y, Hu Y, Zhou T, Zhou KK, Mott R, Wu M, Boulton M, Lyons TJ, Gao G and Ma JX: Activation of the Wnt pathway plays a pathogenic role in diabetic retinopathy in humans and animal models. Am J Pathol 175: 2676-2685, 2009.

85. Konson A, Pradeep S, D'Acunto CW and Seger R: Pigment epithelium-derived factor and its phosphomimetic mutant induce JNK-Dependent apoptosis and P38-mediated migration arrest. Cell Physiol Biochem 49: 512-529, 2018.

86. Yang J, Duh EJ, Caldwell RB and Behzadian MA Antipermeability function of PEDF involves blockade of the MAP kinase/GSK/beta-catenin signaling pathway and uPAR expression. Invest Ophthalmol Vis Sci 51: 3273-3280, 2010.

87. Notari L, Arakaki N, Mueller D, Meier S, Amaral J and Becerra SP: Pigment epithelium-derived factor binds to cell-surface F(1)-ATP synthase. FEBS J 277: 2192-2205, 2010.

88. Cai J, Wu L, Qi X, Li Calzi S, Caballero S, Shaw L, Ruan Q, Grant MB and Boulton ME: PEDF regulates vascular permeability by a Y-secretase-mediated pathway. PLoS One 6: e21164, 2011.

89. Chai KX, Ma JX, Murray SR, Chao J and Chao L: Molecular cloning and analysis of the rat kallikrein-binding protein gene. J Biol Chem 266: 16029-16036, 1991.

90. Miao RQ, Agata J, Chao L and Chao J: Kallistatin is a new inhibitor of angiogenesis and tumor growth. Blood 100: 3245-3252, 2002 .

91. Jenkins AJ, McBride JD, Januszewski AS, Karschimkus CS, Zhang B, O'Neal DN, Nelson CL, Chung JS, Harper CA, Lyons TJ and Ma JX: Increased serum kallistatin levels in type 1 diabetes patients with vascular complications. J Angiogenes Res 2: 19, 2010

92. McBride JD, Jenkins AJ, Liu X, Zhang B, Lee K, Berry WL, Janknecht R, Griffin CT, Aston CE, Lyons TJ, et al: Elevated circulation levels of an antiangiogenic SERPIN in patients with diabetic microvascular complications impair wound healing through suppression of Wnt signaling. J Invest Dermatol 134: $1725-1734,2014$

93. Liu X, Zhang B, McBride JD, Zhou K, Lee K, Zhou Y, Liu Z and Ma JX: Antiangiogenic and antineuroinflammatory effects of kallistatin through interactions with the canonical Wnt pathway. Diabetes 62: 4228-4238, 2013

94. Lawler J: Thrombospondin-1 as an endogenous inhibitor of angiogenesis and tumor growth. J Cell Mol Med 6: 1-12, 2002.

95. Isenberg JS, Ridnour LA, Perruccio EM, Espey MG, Wink DA and Roberts DD: Thrombospondin-1 inhibits endothelial cell responses to nitric oxide in a cGMP-dependent manner. Proc Natl Acad Sci USA 102: 13141-13146, 2005.

96. Sorenson CM, Wang S, Gendron R, Paradis H and Sheibani N Thrombospondin-1 deficiency exacerbates the pathogenesis of diabetic retinopathy. J Diabetes Metab S12: 10.4172/2155-6156. S12-005, 2013.

97. Lawler J: The functions of thrombospondin-1 and -2. Curr Opin Cell Biol 12: 634-640, 2000

98. Armstrong LC and Bornstein P: Thrombospondins 1 and 2 function as inhibitors of angiogenesis. Matrix Biol 22: 63-71, 2003.

99. Mandler WK, Nurkiewicz TR, Porter DW, Kelley EE and Olfert IM: Microvascular dysfunction following multiwalled carbon nanotube exposure is mediated by thrombospondin-1 receptor CD47. Toxicol Sci 165: 90-99, 2018.

100. Ku CH, White KE, Dei Cas A, Hayward A, Webster Z, Bilous R, Marshall S, Viberti G and Gnudi L: Inducible overexpression of sFlt-1 in podocytes ameliorates glomerulopathy in diabetic mice. Diabetes 57: 2824-2833, 2008.

101. Kosugi T, Nakayama T, Li Q, Chiodo VA, Zhang L, Campbell-Thompson M, Grant M, Croker BP and Nakagawa T: Soluble Flt-1 gene therapy ameliorates albuminuria but accelerates tubulointerstitial injury in diabetic mice. Am J Physio Renal Physiol 298: F609-F616, 2010.

102. Bergmann A, Ahmad S, Cudmore M, Gruber AD, Wittschen P, Lindenmaier W, Christofori G, Gross V, Gonzalves ACh, Gröne HJ, et al: Reduction of circulating soluble Flt-1 alleviates preeclampsia-like symptoms in a mouse model. J Cell Mol Med 14: 1857-1867, 2010

103. Watanabe K, Hasegawa Y, Yamashita H, Shimizu K, Ding Y, Abe M, Ohta H, Imagawa K, Hojo K, Maki H, et al: Vasohibin as an endothelium-derived negative feedback regulator of angiogenesis. J Clin Invest 114: 898-907, 2004. 
104. Sonoda H, Ohta H, Watanabe K, Yamashita H, Kimura H and Sato Y: Multiple processing forms and their biological activities of a novel angiogenesis inhibitor vasohibin. Biochem Biophys Res Commun 342: 640-646, 2006.

105. Suzuki Y, Kobayashi M, Miyashita H, Ohta H, Sonoda H and Sato Y: Isolation of a small vasohibin-binding protein (SVBP) and its role in vasohibin secretion. J Cell Sci 123: 3094-3101, 2010.

106. Kozako T, Matsumoto N, Kuramoto Y, Sakata A, Motonagare R, Aikawa A, Imoto M, Toda A, Honda S, Shimeno H and Soeda S: Vasohibin induces prolyl hydroxylase-mediated degradation of hypoxia-inducible factor- $1 \alpha$ in human umbilical vein endothelial cells. FEBS Lett 586: 1067-1072, 2012.

107. Sato Y: Novel link between inhibition of angiogenesis and tolerance to vascular stress. J Atheroscler Thromb 22: 327-334, 2015

108. Miyashita H, Watanabe T, Hayashi H, Suzuki Y, Nakamura T, Ito S, Ono M, Hoshikawa Y, Okada Y, Kondo T and Sato Y: Angiogenesis inhibitor vasohibin-1 enhances stress resistance of endothelial cells via induction of SOD2 and SIRT1. PLoS One 7: e46459, 2012

109. Kosaka T, Miyazaki Y, Miyajima A, Mikami S, Hayashi Y, Tanaka N, Nagata H, Kikuchi E, Nakagawa K, Okada Y, et al: The prognostic significance of vasohibin-1 expression in patients with prostate cancer. Br J Cancer 108: 2123-2129, 2013.

110. Hinamoto N, Maeshima Y, Yamasaki H, Nasu T, Saito D, Watatani H, Ujike H, Tanabe K, Masuda K, Arata Y, et al: Exacerbation of diabetic renal alterations in mice lacking vasohibin-1. PLoS One 9: e107934, 2014.

111. Watatani H, Maeshima Y, Hinamoto N, Yamasaki H, Ujike H, Tanabe K, Sugiyama H, Otsuka F, Sato Y and Makino H: Vasohibin-1 deficiency enhances renal fibrosis and inflammation after unilateral ureteral obstruction. Physiol Rep 2: e12054, 2014.

112. He W, Tan RJ, Li Y, Wang D, Nie J, Hou FF and Liu Y: Matrix metalloproteinase-7 as a surrogate marker predicts renal Wnt/ß-catenin activity in CKD. J Am Soc Nephrol 23: 294-304 2012 .

113. O'Reilly MS, Boehm T, Shing Y, Fukai N, Vasios G, Lane WS, Flynn E, Birkhead JR, Olsen BR and Folkman J: Endostatin: An endogenous inhibitor of angiogenesis and tumor growth. Cell 88: 277-285, 1997

114. Yamaguchi N, Anand-Apte B,Lee M, Sasaki T, Fukai N, Shapiro R Que I, Lowik C, Timpl R and Olsen BR: Endostatin inhibits VEGF-induced endothelial cell migration and tumor growth independently of zinc binding. EMBO J 18: 4414-4423, 1999.

115. Sudhakar A, Sugimoto H, Yang C, Lively J, Zeisberg M and Kalluri R: Human tumstatin and human endostatin exhibi distinct antiangiogenic activities mediated by alpha $\mathrm{v}$ beta 3 and alpha 5 beta 1 integrins. Proc Natl Acad Sci USA 100 4766-4771, 2003

116. Ichinose K, Maeshima $\mathrm{Y}$, Yamamoto $\mathrm{Y}$, Kitayama $\mathrm{H}$, Takazawa Y, Hirokoshi K, Sugiyama H, Yamasaki Y, Eguchi K and Makino H: Antiangiogenic endostatin peptide ameliorates renal alterations in the early stage of a type 1 diabetic nephropathy model. Diabetes 54: 2891-2903, 2005.

117. Carlsson AC, Ostgren CJ, Lanne T, Larsson A, Nystrom FH and Arnlov J: The association between endostatin and kidney disease and mortality in patients with type 2 diabetes. Diabetes Metab 42: 351-357, 2016.

118. Maeshima Y, Colorado PC, Torre A, Holthaus KA Grunkemeyer JA, Ericksen MB, Hopfer H, Xiao Y, Stillman IE and Kalluri R: Distinct antitumor properties of a type IV collagen domain derived from basement membrane. J Biol Chem 275: 21340-21348, 2000.

119. Hamano Y, Zeisberg M, Sugimoto H, Lively JC, Maeshima Y, Yang C, Hynes RO, Werb Z, Sudhakar A and Kalluri R: Physiological levels of tumstatin, a fragment of collagen IV alpha3 chain, are generated by MMP-9 proteolysis and suppress angiogenesis via alphaV beta3 integrin. Cancer Cell 3: 589-601, 2003.

120. Maeshima Y, Sudhakar A, Lively JC, Ueki K, Kharbanda S, Kahn CR, Sonenberg N, Hynes RO and Kalluri R: Tumstatin, an endothelial cell-specific inhibitor of protein synthesis. Science 295: 140-143, 2002.

121. Yamamoto Y, Maeshima Y, Kitayama H, Kitamura S, Takazawa Y, Sugiyama H, Yamasaki Y and Makino H: Tumstatin peptide, an inhibitor of angiogenesis, prevents glomerular hypertrophy in the early stage of diabetic nephropathy. Diabetes 53: 1831-1840, 2004.

122. Wei C, Moller CC, Altintas MM, Li J, Schwarz K, Zacchigna S, Xie L, Henger A, Schmid H, Rastaldi MP, et al: Modification of kidney barrier function by the urokinase receptor. Nat Med 14: $55-63,2008$
123. O'Reilly MS, Holmgren L, Shing Y, Chen C, Rosenthal RA, Moses M, Lane WS, Cao Y, Sage EH and Folkman J: Angiostatin, a novel angiogenesis inhibitor that mediates the suppression of metastases by a Lewis lung carcinoma. Cell 79: 315-328, 1994.

124.Zhang SX, Wang JJ, Lu K, Mott R, Longeras R and Ma JX Therapeutic potential of angiostatin in diabetic nephropathy. J Am Soc Nephrol 17: 475-486, 2006

125. Mu W, Long DA, Ouyang X, Agarwal A, Cruz PE, Roncal CA, Nakagawa T, Yu X, Hauswirth WW and Johnson RJ: Angiostatin overexpression is associated with an improvement in chronic kidney injury by an anti-inflammatory mechanism. Am J Physiol Renal Physiol 296: F145-F152, 2009.

126. Cao Y, Chen A, An SS, Ji RW, Davidson D and Llinas M: Kringle 5 of plasminogen is a novel inhibitor of endothelial cell growth. J Biol Chem 272: 22924-22928, 1997.

127. Zhang SX, Sima J, Shao C, Fant J, Chen Y, Rohrer B, Gao G and Ma JX: Plasminogen kringle 5 reduces vascular leakage in the retina in rat models of oxygen-induced retinopathy and diabetes. Diabetologia 47: 124-131, 2004

128. Li L, Yao YC, Gu XQ, Che D, Ma CQ, Dai ZY, Li C, Zhou T, Cai WB, Yang ZH, et al: Plasminogen kringle 5 induces endothelial cell apoptosis by triggering a voltage-dependent anion channel 1 (VDAC1) positive feedback loop. J Biol Chem 289 32628-32638, 2014

129. Jiao X, Zhang D, Hong Q, Yan L, Han Q, Shao F, Cai G, Chen $X$ and Zhu H: Netrin-1 works with UNC5B to regulate angiogenesis in diabetic kidney disease. Front Med 14 293-304, 2020

130. Pofi R, Fiore D, De Gaetano R, Panio G, Gianfrilli D, Pozza C, Barbagallo F, Xiang YK, Giannakakis K, Morano S, et al: Phosphodiesterase-5 inhibition preserves renal hemodynamics and function in mice with diabetic kidney disease by modulating miR-22 and BMP7. Sci Rep 7: 44584, 2017.

131. Liu J, Hou W, Guan T, Tang L, Zhu X, Li Y, Hou S, Zhang J, Chen $\mathrm{H}$ and Huang Y: Slit2/Robol signaling is involved in angiogenesis of glomerular endothelial cells exposed to a diabetic-like environment. Angiogenesis 21: 237-249, 2018

132. Hernandez-Diaz I, Pan J, Ricciardi CA, Bai X, Ke J, White KE, Flaquer M, Fouli GE, Argunhan F, Hayward AE, et al: Overexpression of circulating soluble Nogo-B improves diabetic kidney disease by protecting the vasculature. Diabetes 68: 1841-1852, 2019.

133. Sulaiman MK: Diabetic nephropathy: Recent advances in pathophysiology and challenges in dietary management. Diabetol Metab Syndr 11: 7, 2019

134. Wilson PC, Wu H, Kirita Y, Uchimura K, Ledru N, Rennke HG, Welling PA, Waikar SS and Humphreys BD: The single-cell transcriptomic landscape of early human diabetic nephropathy. Proc Natl Acad Sci USA 116: 19619-19625, 2019.

135. Berl T: Angiotensin-converting enzyme inhibitors versus AT1 receptor antagonist in cardiovascular and renal protection, the case for AT1 receptor antagonist. J Am Soc Nephrol 15 (Suppl 1): S71-S76, 2004

136. Hilgers KF and Mann JF: ACE inhibitors versus AT(1) receptor antagonists in patients with chronic renal disease. J Am Soc Nephrol 13: 1100-1108, 2002.

137. Zhu X, Wu S, Dahut WL and Parikh CR: Risks of proteinuria and hypertension with bevacizumab, an antibody against vascular endothelial growth factor, systematic review and meta-analysis. Am J Kidney Dis 49: 186-193, 2007.

138. Cossey LN, Hennigar RA, Bonsib S, Gown AM and Silva FG: Vascular mesangial channels in human nodular diabetic glomerulopathy. Hum Pathol 48: 148-153, 2016.

139. Elsherbiny NM, El-Sherbiny M and Said E: Amelioration of experimentally induced diabetic nephropathy and renal damage by nilotinib. J Physiol Biochem 71: 635-648, 2015.

140. Touzani F, Geers C and Pozdzik A: Intravitreal injection of Anti-VEGF antibody induces glomerular endothelial cells injury. Case Rep Nephrol 2019: 2919080, 2019.

141. Hanna RM, Lopez EA, Hasnain H, Selamet U, Wilson J, Youssef PN, Akladeous N, Bunnapradist S and Gorin MB: Three patients with injection of intravitreal vascular endothelial growth factor inhibitors and subsequent exacerbation of chronic proteinuria and hypertension. Clin Kidney J 12: 92-100, 2019

142. Watanabe D, Suzuma K, Suzuma I, Ohashi H, Ojima T, Kurimoto M, Murakami T, Kimura T and Takagi H: Vitreous levels of angiopoietin 2 and vascular endothelial growth factor in patients with proliferative diabetic retinopathy. Am J Ophthalmol 139: 476-481, 2005. 
143. Popescu M, Bogdan C, Pintea A, Rugina D and Ionescu C: Antiangiogenic cytokines as potential new therapeutic targets for resveratrol in diabetic retinopathy. Drug Des Devel Ther 12: 1985-1996, 2018.

144. Senet P: Becaplermin gel (Regranex gel). Ann Dermatol Venereol 131: 351-358, 2004 (In French).

145. Brem H and Tomic-Canic M: Cellular and molecular basis of wound healing in diabetes. J Clin Invest 117: 1219-1222, 2007.

146. Fernandez-MontequinJI,Valenzuela-SilvaCM,DiazOG,SavigneW, Sancho-Soutelo N, Rivero-Fernandez F, Sanchez-Penton P, Morejon-Vega L, Artaza-Sanz H, García-Herrera A, et al: Intra-lesional injections of recombinant human epidermal growth factor promote granulation and healing in advanced diabetic foot ulcers: Multicenter, randomised, placebo-controlled, double-blind study. Int Wound J 6: 432-443, 2009.

147. Uchi H, Igarashi A, Urabe K, Koga T, Nakayama J, Kawamori R, Tamaki K, Hirakata H, Ohura T and Furue M: Clinical efficacy of basic fibroblast growth factor (bFGF) for diabetic ulcer. Eur J Dermatol 19: 461-468, 2009.
148. Jude EB, Blakytny R, Bulmer J, Boulton AJ and Ferguson MW: Transforming growth factor-beta 1,2,3 and receptor type I and II in diabetic foot ulcers. Diabet Med 19: 440-447, 2002.

149. Blakytny R, Jude EB, Martin Gibson J, Boulton AJ and Ferguson MW: Lack of insulin-like growth factor 1 (IGF1) in the basal keratinocyte layer of diabetic skin and diabetic foot ulcers. J Pathol 190: 589-594, 2000.

150. Virgili G, Parravano M, Evans JR, Gordon I and Lucenteforte E: Anti-vascular endothelial growth factor for diabetic macular oedema: A network meta-analysis. Cochrane Database Syst Rev 10: CD007419, 2018

This work is licensed under a Creative Commons Attribution-NonCommercial-NoDerivatives 4.0 International (CC BY-NC-ND 4.0) License. 